\title{
An Efficient and Robust Hybrid Routing Protocol for Corroboration of Node Auto-configuration In MANET
}

\author{
A. Santhiya ${ }^{1}$ and R. Bhairavi ${ }^{2}$ \\ ${ }^{1}$ P.G Student (M.TECH), Department of ECE, RGCET-Pondicherry University, \\ Pondicherry-India \\ ${ }^{2}$ P.G Student (M.TECH), Department of ECE, RGCET-Pondicherry University, \\ Pondicherry-India \\ 1'asanthiya23@gmail.com, ${ }^{2}$ bhaiuu2312@gmail.com
}

\begin{abstract}
Address assignment is a key challenge in ad hoc networks due to the lack of infrastructure. For autonomous addressing routing protocols require a distributed and self-managed mechanism to avoid address collisions in a dynamic network with fading channels and joining/leaving nodes. The propose and analyze a lightweight hybrid protocol that configures mobile ad hoc nodes based on a distributed address database stored in filters i.e. unreliable wireless links by utilizing the local path diversity that reduces the control load and makes the proposal robust to packet losses and network partitions. For evaluate the performance of our protocol, considering joining nodes and network initialization. Simulation results show that our protocol resolves all the address collisions and also reduces the control traffic when compared to previously proposed protocols. Hybrid routing protocol remarkably improves the packet delivery ratio, while maintaining high energy efficiency and low delivery latency.
\end{abstract}

Keywords: Reactive and Proactive Protocols Comparison, Mobile ad hoc network, Hybrid Routing Protocol, AODV, Broadcast Reply (BR), etc

\section{Introduction}

Wireless networks provide connection flexibility between users in different places. Moreover, the network can be extended to any place or building without the need for a wired connection. Wireless networks are classified into two categories Infrastructure networks and Ad Hoc networks [1]. An Access Point (AP) represents a central coordinator for all nodes. Any node can be joining the network through AP. In addition, AP organizes the connection between the Basic Set Services (BSSs) so that the route is ready when it is needed. However, one drawback of using an infrastructure network is the large overhead of maintaining the routing tables is known as Infrastructure networks.

A wireless ad hoc network is a decentralized type of wireless network. The network is ad hoc because it does not rely on a preexisting infrastructure, such as routers in wired networks or access points in managed (infrastructure) wireless networks. Ad Hoc networks do not have a certain topology or a central coordination point. Therefore, sending and receiving packets are more complicated than infrastructure network is known as Ad Hoc network [10]. Nowadays, with the immense growth in wireless network applications like handheld computers and cell phones researchers are encouraged to improve the network services and performance. One of the challenging design issues in wireless Ad Hoc networks is supporting mobility in Mobile Ad Hoc Networks (MANETs) [11].

The mobility of nodes in MANETs increases the complexity of the routing protocols and the degree of connections flexibility. However, the flexibility of allowing nodes to 
join, leave, and transfer data to the network pose security challenge. A MANET is a collection of mobile nodes sharing a wireless channel without any centralized control or established communication backbone. MANET has dynamic topology and each mobile node has limited resources such as battery, processing power and on-board memory. This kind of infrastructure-less network is very useful in situation in which ordinary wired networks is not feasible like battlefields, natural disasters etc. The nodes which are in the transmission range of each other communicate directly otherwise communication is done through intermediate nodes which are willing to forward packet hence these networks are also called as multi-hop networks.

\section{Literature Review}

Reactive routing protocol $[6,8]$ creates routes only when desired by the source node. When a node requires a route to a destination, it initiates a route discovery process within the network. This process is completed once a route is found or all possible route permutations have been examined. Once a route has been established, it is maintained by a route maintenance procedure until either the destination becomes inaccessible along every path from the source or until the route is no longer desired. The Ad hoc Ondemand Distance Vector (AODV) [6, 8, 9] protocol, one of the reactive routing protocol that has receive the most attention, however, does not utilize multiple paths. In AODV $[2,6]$, at every instance, route discovery is done for fresh communication which consumes more bandwidth and causes more routing overhead. The data packets will be lost during path break which occurs due to node mobility. When the network traffic requires real time delivery (voice, for instance), dropping data packets at the intermediate nodes can be costly. Likewise, if the session is a best effort, TCP connection, packet drops may lead to slow start, timeout, and throughput degradation [14].

Zone routing protocol is a hybrid routing protocol which effectively combines the best features of proactive [5] and reactive routing protocol [2, 17]. The key concept is to use a proactive routing scheme within a limited zone in the r-hop neighborhood of every node, and use reactive routing scheme for nodes beyond this zone. An Intra-zone routing protocol (IARP) is used in the zone where particular node employs proactive routing whereas inter-zone routing protocol (IERP) is used outside the zone. Proactive protocols attempt to continuously evaluate the routes within the network. So that when a packet needs to be forwarded, the route is already known and can be immediately used it can be the comparison of proactive routing protocol [16] is summarized in. The distance vector protocol is an example of a proactive scheme [5].

Destination- Sequenced-Distance-Vector Routing [5] is the table driven routing based on classical Bellman-ford routing mechanism. Every mobile node in the network maintains routing table in which all of the possible destinations within the network and the number of hops to each destination are recorded. Each entry is marked with the sequence number assigned by the destination node which is used to avoid formation of routing loops. Routing table updates are periodically transmitted in order to maintain consistency. The main disadvantage is that the DSDV protocol suffers from excessive control overhead that is proportional to the number of nodes in the network and therefore is not scalable in ad hoc wireless network.

\section{Research Methodology}

\subsection{Existing System}

Figure 1 illustrates an overview of the functional architecture of Reliable Reactive Routing Enhancement (R3E) [3], which is a middle-ware design across the MAC and 
the network layers to increase the resilience to link dynamics for WSNs/IWSNs. The $\mathrm{R} 3 \mathrm{E}$ enhancement layer consists of three main modules, the reliable route discovery module, the potential forwarder selection and prioritization module, and the forwarding decision module. The helper node and potential forwarder are interchangeable in this work. The reliable route discovery module finds and maintains the route information for each node. During the route discovery phase, each node involved in the cooperative forwarding process stores the downstream neighborhood information, that is to say, when a node serves as a forwarder, it already knows the next-hop forwarding candidates along the discovered path. The other two modules are responsible for the runtime forwarding phase.

When a node successfully receives a data packet, the forwarding decision module checks whether it is one of the intended receivers. If yes, this node will cache the incoming packet and start a back off timer to return an ACK message, where the timer value is related with its ranking in the intended receiver list (called forwarding candidate list). If there is no other forwarder candidate with higher priority transmitting an ACK before its back off timer expires, it will broadcast an ACK and deliver the packet to the upper layer, i.e., trigger a receiving event in the network layer. Then, the potential forwarder selection and prioritization module attaches the ordered forwarder list in the data packet header for the next hop. Finally, the outgoing packet will be submitted to the MAC layer and forwarded towards the destination.

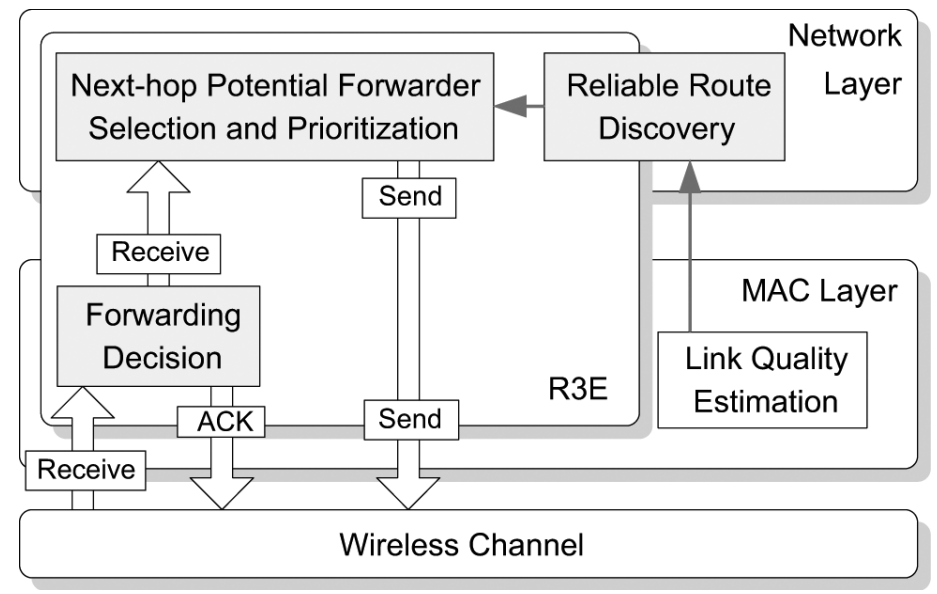

Figure 1. Functional Architecture Overview of R3E

\subsubsection{Issues in Existing System}

- The efficiency of transmission is not sufficient.

- In between, the nodes cannot detect the collision.

- It cannot achieve the load balance.

Periodic beaconing can cause the inaccurate local topologies in highly mobile ad-hoc networks, which lead to performances degradation, e.g. frequent packet loss and longer delay see in table 3.1 [7]. The outdated entries in the neighbor list are the major source that decreases the performance [13].

\subsection{Proposed System}

There is a trade-off between proactive and reactive protocols [4]. Proactive protocols have large overhead and less latency while reactive protocols have less overhead and more latency. So a Hybrid protocol is presented to overcome the shortcomings of both proactive and reactive routing protocols. Hybrid routing protocol is 
Table 3.1 Comparison between Three Routing Protocol with its Parameter

\begin{tabular}{|c|c|c|c|}
\hline PARAMETERS & $\begin{array}{l}\text { REACTIVE } \\
\text { PROTOCOL }\end{array}$ & $\begin{array}{l}\text { PROACTIVE } \\
\text { PROTOCOL }\end{array}$ & $\begin{array}{l}\text { HYBRID } \\
\text { PROTOCOL }\end{array}$ \\
\hline $\begin{array}{l}\text { Routing } \\
\text { Philosophy }\end{array}$ & Flat & Flat/Hierarchical & Hierarchical \\
\hline $\begin{array}{l}\text { Routing scheme } \\
\text { [15] }\end{array}$ & On demand & Table driven & $\begin{array}{l}\text { Combination of } \\
\text { both }\end{array}$ \\
\hline $\begin{array}{l}\text { Routing } \\
\text { overhead[15] }\end{array}$ & Low & High & Medium \\
\hline Latency [12] & $\begin{array}{l}\text { High due to } \\
\text { flooding }\end{array}$ & $\begin{array}{l}\text { Low due to } \\
\text { Routing table }\end{array}$ & $\begin{array}{l}\text { Inside zone low } \\
\text { outside similar } \\
\text { to Reactive } \\
\text { protocol }\end{array}$ \\
\hline Scalability level & $\begin{array}{l}\text { Not suitable for } \\
\text { large network }\end{array}$ & Low & $\begin{array}{l}\text { Designed for } \\
\text { large network }\end{array}$ \\
\hline $\begin{array}{l}\text { Availability of } \\
\text { routing } \\
\text { information }\end{array}$ & $\begin{array}{l}\text { Available when } \\
\text { required }\end{array}$ & $\begin{array}{l}\text { Always available } \\
\text { stored in table }\end{array}$ & $\begin{array}{l}\text { Combination of } \\
\text { both }\end{array}$ \\
\hline Periodic Updates & $\begin{array}{l}\text { Not needed as } \\
\text { route available } \\
\text { on demand }\end{array}$ & $\begin{array}{l}\text { Yes whenever the } \\
\text { topology of the } \\
\text { network changes }\end{array}$ & $\begin{array}{l}\text { Yes needed } \\
\text { inside the zone }\end{array}$ \\
\hline Storage capacity & $\begin{array}{l}\text { Low generally } \\
\text { depends upon } \\
\text { the number of } \\
\text { routes }\end{array}$ & $\begin{array}{l}\text { High due to the } \\
\text { routing table }\end{array}$ & $\begin{array}{l}\text { Depends on the } \\
\text { size of zone } \\
\text { inside the zone } \\
\text { sometimes high } \\
\text { as proactive } \\
\text { protocol }\end{array}$ \\
\hline Mobility s & $\begin{array}{l}\text { Route } \\
\text { maintenance }\end{array}$ & $\begin{array}{l}\text { Periodical } \\
\text { updates }\end{array}$ & $\begin{array}{l}\text { Combination of } \\
\text { both }\end{array}$ \\
\hline
\end{tabular}

combination of both proactive and reactive routing protocol. Hybrid Routing protocol (HRP) is a network routing protocol that combines Distance Vector Routing protocol (DVRP) and Link State Routing protocol (LSRP) features. HRP is used to determine optimal network destination routes and report network topology data modifications. HRP is also known as Balanced Hybrid Routing (BHR).HRP features are as follows: Requires less memory and processing power than LSRP, Integrates reactive and proactive routing advantages and Serves activated nodes via reactive flooding.

RREP packet is broadcast to all neighbors who are in the coverage area of the replying node. The RREP packet is broadcast to all neighbor nodes along with intended node. On receiving RREP packet, neighboring node makes an entry in the routing table about complete path which has received in RREP. If neighboring node is not the intended node, it drops RREP packet. If it is intended node, it adds own id in the received path and rebroadcast RREP [18]. This process of extracting useful information from RREP packet and updates of RREP packet is carried out until RREP packet is not received by the destination which is source of RREQ packet. Figure .2 shows the process of RREP packet transmission. In the Figure .2, node 14 is sending a RREP packet is response to RREQ from node 0 . Routing table at node 14 after processing RREQ packet from node 0 is shown in figure. At node 14 the next hop towards node 0 is node 11 with node 11 as intended node. It prepares RREP packet and broadcast with node 11 as the intended node. Neighboring node 11, 12, 13 will receives the RREP 
packet. The nodes which are not intended node will drop the RREP packet after updating the routing table.

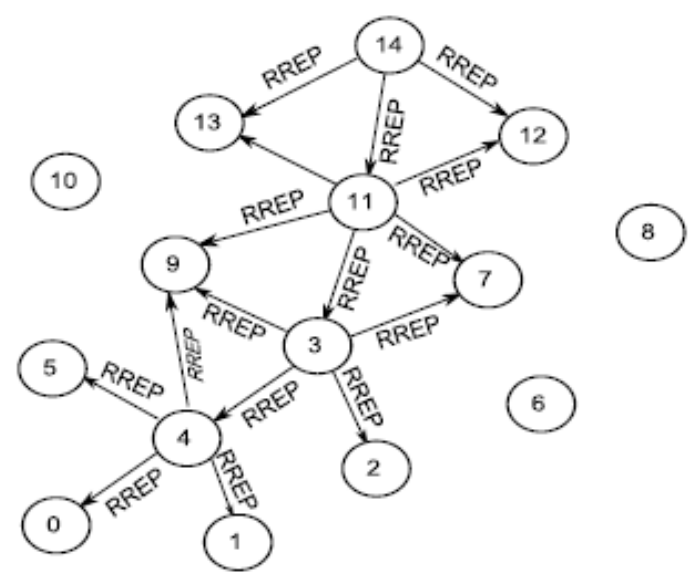

Figure 2. RREP Transmission in the Network

This process is repeated until RREP packet is reached to the destination node $O$ which is source of RREQ packet. The process of RREP packet transmission is as shown in the Figure 2. As the number of CBR data traffic increases, more and more information are added to the routing table. Suppose node 13 want to communicate with node 2. In the routing table of node 13 as shown in Figure 2, there exist a path to node 2. There is no need for route discovery as it usually happen in reactive protocol. Node 13 can immediately start transmitting data to node 2 .

Consider few more CBR data traffic as follows

- CBR 1: from node 9 to node 0 starts at 4.0 and ends at 6.0 .

- CBR 2: from node 1 to node 11 starts at 5.0 and ends at 7.0.

- CBR 3: from node 5 to node 14 starts at 8.0 and ends at 9.0.

- CBR 4: from node 2 to node 13 starts at 10.0 and ends at 12.0.

\section{Experimental Result}

REPF [19]: REPF (Reliable and Efficient Packet Forwarding) protocol is designed to improve the AODV routing performance by utilizing local path diversity. The route discovery phase finds an efficient primary path (composed of a set of primary forwarding nodes) in terms of the accumulated path ETX, and alternative paths which have similar cost. However, REPF restricts the helper nodes to a very limited scope, i.e., only the nodes which can connect the two-hop away primary forwarding nodes are considered as helper nodes, as shown in Figure 2. As a result, it does not fully utilize the forwarding opportunities provided by available neighboring nodes in evenly distributed networks.

Module Descriptions

In this thesis explains routing protocol efficiency based on their types of either reactive or proactive based protocol are used for node auto configurations of its own position addressing of the node. It contains four modules as follows: node creation module, sending beaconing information, mobility prediction module and protocol connection module. In that first module describes node creation it need number node to be deployed in various locations as shown in Figure .3. At the same time fixed the node mobility position will be in random order. Why because network setup are in infra structure less mode, in MANET network are in mobile in nature so it need mobility. Wireless Sensor network is created with the total number of wireless nodes. Nodes are 
configured with simulation parameters listed in the simulation model table. Nodes are deployed in the initial location. After the deployment, each node identifies its neighbors by sending beacon. Nodes which are located within the communication range are known as neighbors. Each node broadcast the beacon to its neighbors.

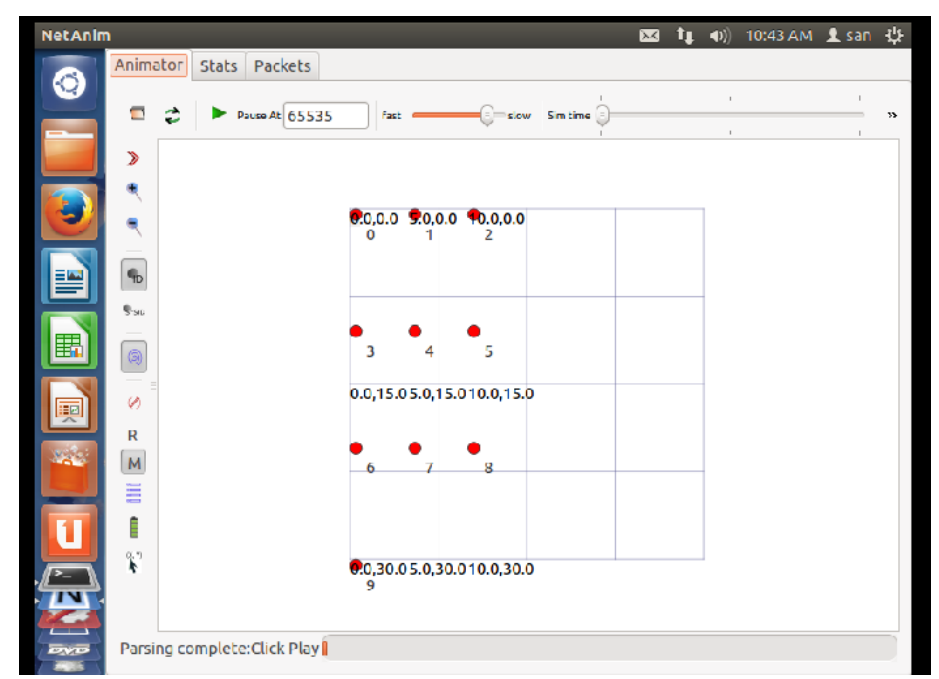

Figure 3. Node Creation Output

In second module, the after triggering the router node, the node initialization process is carried out. Then, the beacon packets are transmitted to all the nodes in the network in Figure 4. In this module, we check the nodes distance between previous position and current position. The node distance greater than acceptable threshold update their position to its neighbors through beacon packets.

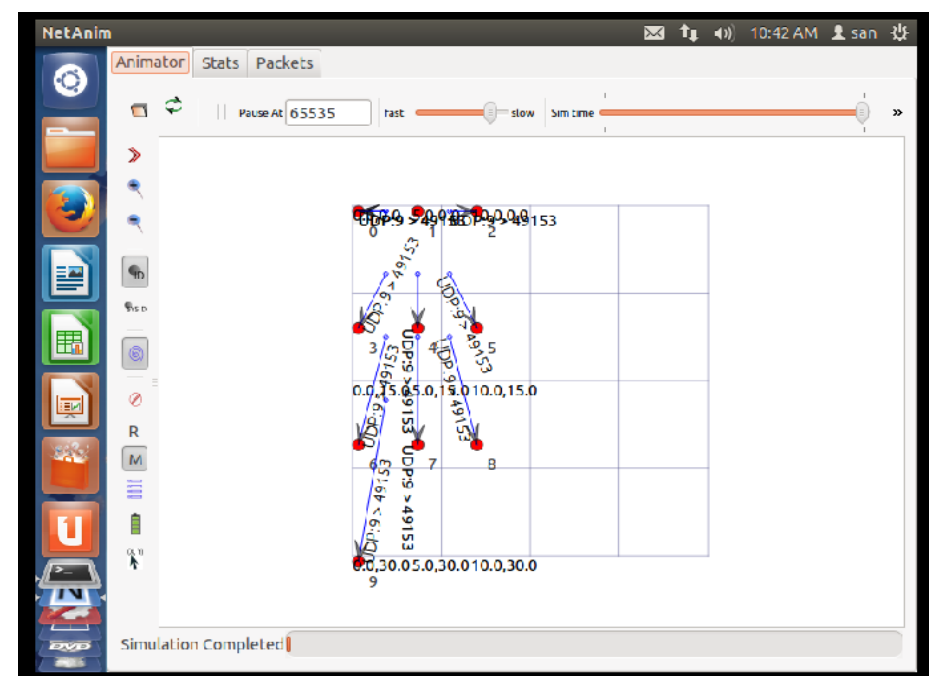

Figure 4. Beacon Information through RREQ

The third module computation overhead involved in the content distribution consists of two parts. The first part is the cost due to the verification of the packets, and the second part is the cost due to the need to compute random combinations of the data blocks as shown in Figure 5. The preceding sections of this paper focus on the first part of the cost, which can be reduced through the use of more efficient hash functions and batch verification techniques as we have discussed. 


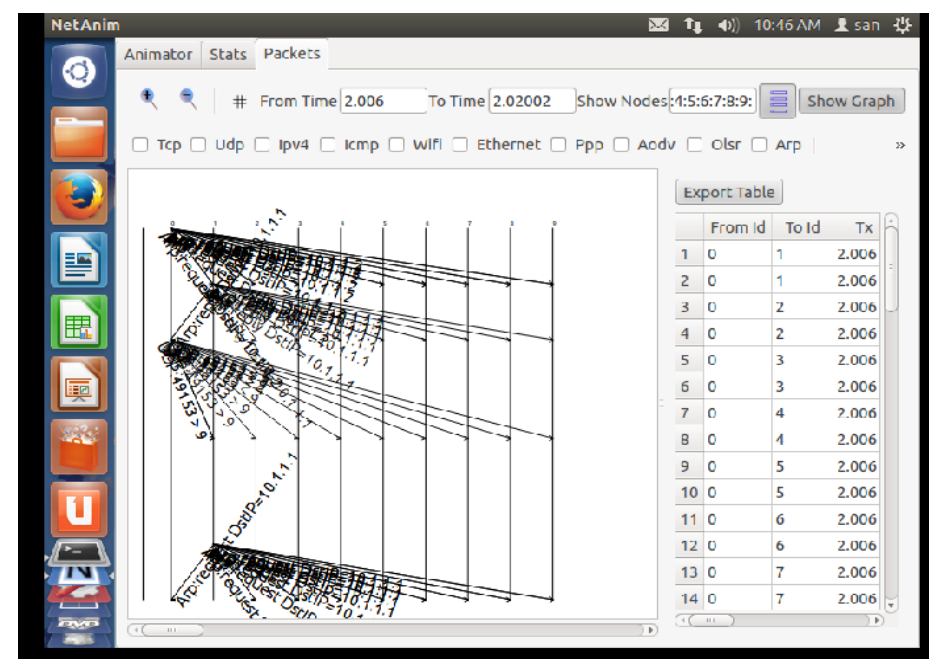

Figure 5. Mobility Predicted Output

\section{Conclusion}

This thesis totally speaks about working and description of Reactive and Proactive Protocols and every Protocol has its limitations and delimitations. Some time they may work better and sometime not. Many of the research paper have been focused on performance metric for comparing the performance of Routing Protocols. Performance Metric like Packet Delivery Ratio, Throughput, Average End-To-End Delay and Normalized Routing Overhead. For Simulation of Routing Protocols in Wsn mostly used simulation tools are NS2, NS3, NetSim, GloMoSim and Qualnet. There are many issues that require further investigation like traffic control, power control and security. In case of security, due to the broadcast nature of the wireless node security becomes more difficult. Further research is needed to investigate how to stop an intruder from joining an ongoing session or stop a node from receiving packets from other sessions.

\section{References}

[1] J. Broch, D.A. Maltz, D.B. Johnson, Y.C. Hu and J. JetCheva, "A Performance comparison of Multihop wireless Ad-Hoc Network Routing protocols", Mobicom, (1998), vol. 98, pp. 25-30, Dallas, Texas.

[2] D.B. Johnson and D.A. Maltz, "Protocols for Adaptive Wireless and Mobile Computing", Prentice In IEEE Personal Communications, vol. 3, no. 1, (1996).

[3] C. Murthy, S. Ram, "Ad Hoc Wireless Networks: Architectures and protocols", Prentice In IEEE Personal Communications, vol. 3, no. 1, (1996).

[4] J. Niu, L. Cheng,Yugu, L. Shu and K.D. Sajal, "R3e: Reliable Reactive Routing Enhancement For Wireless Sensor Networks Transactions On Industrial Informatics", IEEE, vol. 10, no. 1, (2014).

[5] Hybrid Routing Protocol with Broadcast Reply for Mobile Ad hoc Network, (92010 International Journal of Computer Applications (0975-8887), vol. 1, no. 1.

[6] C.P.P. Bhagwat, "Highly Dynamic Destination Sequenced Distance Vector DSDV Routing for Mobile Computers", Proceeding of ACM SIGCOM, (1994), pp. 234-244.

[7] K.A. Agha, M.H. Bertin, T. Dang, A. Guitton, P. Minet, T. Val and J.B. Viollet, "Which wireless technology for industrial wireless sensor networks, the development of Ocari technology", IEEE Trans. Ind.Electron, vol. 56, no. 10, (2009), pp. 4266-4278.

[8] K. Yu, M. Gidlund, J. Åkerberg and M. Björkman, "Reliable RSS-based routing protocol for industrial wireless sensor networks", in Proc. IECON, (2012), pp. 3231-3237.

[9] C.E. Perkins, E.M. Royer, S.R. Das and M.K. Mariana, "Performance Comparison of Two onDemand Routing Protocols for Ad-Hoc Networks", IEEE Personal Communications, (2001), pp. 1628.

[10] S. Ahmed and M.S. Alam, "Performance Evaluation of Important Ad- Hoc Network Protocols", EURASIP Journal on Wireless Communications and Networking, (2006), p. 11.

[11] P.K. Pattanaik and R. Mall, "Challenges in ad hoc networks", Sidhanth Journal, (2007), pp. 153-160. 
[12] M. Woo, S. Singh and C.S. Raghvendra, "Power Aware Routing in Mobile Ad-Hoc Networks", In Proceedings of ACM/IEEE MOBICOM, (1998), pp. 181-190, Dallas, Texas,

[13] K.Y. Wang, R. Dube, C.D. Rais and S.K. Tripathi, "Signal Stability Based Adoptive Routing SSA for Ad hoc Mobile Network", IEEE Personal Communication, vol. 4, (1997), pp. 36-45

[14] J.H. Chang and L. Tassiulas, "Energy Conserving Routing in Wireless Ad hoc Network", In IEEE Conference on Computer Communications.INFOCOM, (2000), pp. 22-3, 1Tel Aviv Israel.

[15] S.R. Das, C.E. Perkins, E.M. Royer and M.K. Marina, "Performance Comparison of Two On-demand Routing Protocols", (C2010 International Journal of Computer Applications (0975- 8887), for Ad hoc Networks, IEEE Personal Communications Magazine Special Issue on Ad hoc Networking, vol. 1, no. 10-113, (2001), pp. 16-28.

[16] D.B. Johnson, "Routing in Ad hoc Networks of Hmobile Hosts", IEEE Workshop on Mobile omputing Systems and Applications, (1994), pp. 158-163.

[17] D.B. Johnson and D.A. Maltz, "Dynamic Source Routing in Ad hoc Wireless Network", In the Book, Mobile Computing, (1996), pp. 153-181.

[18] E. Topalis S. Giannoulis, C. Antonopoulos and S. Koubias, "Zrp Versus DSR and TORA: A Compressive Survey on ZRP Performance", 10th IEEE Conference ETFA 2005, 1(ISBN:0- 78039401-1), (2005).

[19] A. Khetrapal, "Routing Techniques for Mobile Ad hoc Networks Classification and Qualitative/Quantitative Analysis", In ICWN, (2006), pp. 251-257.

[20] W.A. Hoc, J. Wang, H. Zhai, W. Liu, and Y. Fang, "Reliable and efficient packet forwarding by utilizing path diversity in wireless ad hoc networks", in Proceeding IEEE Milcom, (2004), pp. 258264. 